\title{
Commentary: The toll of complicated endocarditis and septic sequela: Old wives' tales and dogma
}

\author{
Victor A. Ferraris, MD, PhD
}

\author{
From the Department of Surgery, University of Kentucky, Lexington, Ky. \\ Disclosures: Author has nothing to disclose with regard to commercial support. \\ Received for publication Oct 25, 2018; accepted for publication Oct 26, 2018; available ahead of print Nov 30, \\ 2018. \\ Address for reprints: Victor A. Ferraris, MD, PhD, Department of Surgery, University of Kentucky, A301 Ken- \\ tucky Clinic, 740 S Limestone, Lexington, KY 40536-0284 (E-mail: ferraris@uky.edu). \\ J Thorac Cardiovasc Surg 2019;157:e227-8 \\ $0022-5223 / \$ 36.00$ \\ Copyright (C) 2018 by The American Association for Thoracic Surgery \\ https://doi.org/10.1016/j.jtcvs.2018.10.119
}

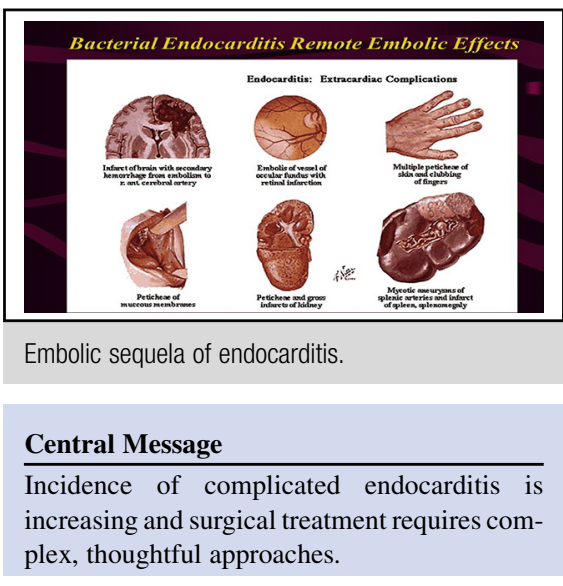

See Article page e223.
Woldendorp and colleagues ${ }^{1}$ present a patient with complicated bloodstream infections involving multiple components of the arterial tree. The authors were challenged by the multiplicity of septic foci in their patient but ultimately ended up with a successful short-term outcome. Their patient had evidence of brain, lung, and abdominal aortic infections that may have originated from an infected mitral valve. The authors used a combination of temporizing endovascular procedures and valve replacement to provide a successful intermediate-term outcome in a very complicated patient.

The management of embolic strokes or other satellite lesions in the setting of a need for cardiac operations related to endocarditis is complex and mostly lacking evidencebased guidance. There are surprisingly few randomized trials or even systematic reviews that deal with managing multifaceted, associated lesions in patients with complex endocarditis. ${ }^{2}$ Arguably, no part of cardiac surgery is more in need of an evidence base than the surgical treatment of complicated endocarditis. Despite optimal care for patients with endocarditis, 1-year mortality approaches $30 \% .^{3}$ Treatment controversies abound, including questions about timing and sequencing of operations, control of peripheral sites of infection, and need for prolonged antibiotics.

An old wives' tale was part of my training. The most senior surgeon pronounced, as if it were gospel, that $80 \%$ of things that embolize from the heart go to the brain. I have no idea where this piece of information came from, but there is probably some truth to it. The case report presented by Woldendorp and colleagues ${ }^{1}$ supports this dogma, but it is unsettling that we may still rely on this type of unverified claim in dealing with complicated endocarditis.

The peer review process gleaned a predictable range of critical comments to the article by Woldendorp and colleagues. ${ }^{1}$ The lack of evidence to support the authors' treatments unleashed a spectrum of reviewer comments that went something like the following:

- "This is nothing new. It is well known that patients with endocarditis can have these multiple embolic showers";

- "The follow-up is too short. There will be further problems down the line that will ultimately be associated with a poor outcome in this patient";

- "The authors should have waited longer after the stroke symptoms to avoid conversion of brain embolic ischemic areas into hemorrhagic strokes"; and

- "Why put this patient on lifetime antibiotics? Doesn't that open up a whole new set of problems related to organism resistance?"

It is easy to be critical of the article by Woldendorp and colleagues. 'However, many of the reviewers' have no more evidence for their comments than the authors do for their treatment plan for this patient. The lack of evidencebased critical comments highlights the dilemma that surgeons face in treating patients with complex endocarditis.

There is no doubt that the incidence of endocarditis is increasing in the United States, ${ }^{4}$ and likely also worldwide. $^{5,6}$ This increase is compounded by endocarditis related to opioid abuse. ${ }^{7}$ A natural projection is that complicated endocarditis with multiple organ involvement and multiple vascular and extravascular sites of infection will be more common. Inevitably, patients with complicated endocarditis, like the patient described by Woldendorp and colleagues, ${ }^{1}$ will become more common. Simple, uncomplicated endocarditis of a heart valve in this new world 
may be the exception, not the rule. As cardiothoracic specialists, we should embrace anecdotal reports like the current article while at the same time lobbying for the accumulation of broader-based evidence sources (eg, systematic reviews or meta-analyses) to help treat these very complicated and high-risk patients.

\section{References}

1. Woldendorp K, Selvaraj CN, Bannon PG, Dubenec S. Simultaneous Enterococcus faecalis mitral valve endocarditis, mycotic aortoiliac, and intracranial aneurysms: a surgical dilemma. J Thorac Cardiovasc Surg. 2019;157:e223-5.

2. Abegaz TM, Bhagavathula AS, Gebreyohannes EA, Mekonnen AB, Abebe TB. Short- and long-term outcomes in infective endocarditis patients: a systematic review and meta-analysis. BMC Cardiovasc Disord. 2017;17:291.
3. Cahill TJ, Baddour LM, Habib G, Hoen B, Salaun E, Pettersson GB, et al. Challenges in infective endocarditis. J Am Coll Cardiol. 2017;69: 325-44.

4. Jackson KA, Bohm MK, Brooks JT, Asher A, Nadle J, Bamberg WM, et al. Invasive methicillin-resistant Staphylococcus aureus infections among persons who inject drugs_-six sites, 2005-2016. MMWR Morb Mortal Wkly Rep. 2018;67: 625-8.

5. Meel R, Essop MR. Striking increase in the incidence of infective endocarditis associated with recreational drug abuse in urban South Africa. S Afr Med J. 2018;108:585-9.

6. Wright A, Otome O, Harvey C, Bowe S, Athan E. The current epidemiology of injecting drug use-associated infective endocarditis in Victoria, Australia, in the midst of increasing crystal methamphetamine use. Heart Lung Circ. 2018;27: 484-8.

7. Ferraris VA, Sekela ME. Missing the forest for the trees: the world around us and surgical treatment of endocarditis. J Thorac Cardiovasc Surg. 2016;152:677-80. 